\title{
Una lectura gramsciana del pensamiento de Paulo Freire
}

\author{
A READING FROM GRAMSCI OF PAULO FREIRE'S THOUght
}

Dr. Luis A. Vivero-Arriagada (luisvive@gmail.com) Departamento de Trabajo Social, Universidad Católica de Temuco (Temuco, Chile)

\begin{abstract}
Historicist and political reflection of Freire, gives us a deep look promising in the world. His conviction that oppressor and oppressed can liberate each other and together build a more just and equal, is embodied in education as an emancipatory praxis, which must be built into a dialogic relationship between teacher and learner. Paulo Freire's postulates it has influence of diverse intellectual currents and in this tour, we find a permanent invocation to Antonio Gramsci's contributions
\end{abstract}

Keywords: Gramsci, hegemony, Paulo Freire, education, emancipation.

\section{Resumen}

La reflexión historicista y política de Freire, nos entrega una mirada profundamente esperanzadora del mundo. Su convicción que opresor y oprimido se pueden liberar mutuamente y en conjunto construir una sociedad más justa e igualitaria, se materializa en la educación como una praxis emancipadora, la cual debe construirse en una relación dialógica entre educador y educando. Los postulados de Paulo Freire tienen influencia de diversas corrientes intelectuales y en ese recorrido, encontramos una permanente invocación a los aportes de Antonio Gramsci.

Palabras clave: Gramsci, hegemonía, Paulo Freire, educación, emancipación.

\section{Introducción}

Para este ensayo, nos planteamos el desafío de relevar la importancia del pensamiento gramsciano, en el aporte político intelectual de Paulo Freire. Pero el aporte o la influencia de Gramsci en el desarrollo del pensamiento freiriano, no lo vemos como una especie de colonialidad del saber eurocéntrico, parafraseando la tesis de Quijano, sino como una síntesis dialéctica de ambos pensamientos, expresados en la realidad material y simbólica de América Latina y también, resignificada a la luz del actual escenario histórico político. 
En este último sentido, estimamos que el nuevo ciclo de conflictividad, instalado desde fines del siglo XX, pone en evidencia la crisis de legitimidad de la hegemonía neoliberal y los estados nacionales. Asimismo este escenario contribuiría no sólo a la emergencia de nuevos sujetos políticos, sino que nuevas prácticas y diversas subjetividades en el campo de lo político, nuevas formas de interpretar la realidad latinoamericana, que se sintetizarían en nuevas formas luchas contra-hegemónicas.

Para abordar el desafío de este ensayo, según lo planteado en el primer párrafo, consideramos necesario partir con la entrega de algunos elementos de lo que Gramsci desarrolla en torno a los conceptos de hegemonía y bloque histórico, y dentro de este proceso, la función que cumplen los intelectuales orgánicos para la producción y reproducción de la ideología de las clases dominantes. Luego de ello nos aventuramos en la articulación de un análisis del pensamiento de Gramsci en Paulo Freire, y por último finalizar con algunos comentarios y reflexiones a la luz del actual contexto sociopolítico latinoamericano, particularmente situado en el caso chileno, con lo que ha sido la conflictividad y cuestionamiento al modelo de educación mercantil.

Cabe considerar que durante el último cuarto del siglo pasado, las reflexiones, interpretaciones y explicaciones de los diferentes procesos que se expresaban en la realidad social, estuvieron hegemonizadas por aquellas corrientes ideológicas de carácter orgánico, que respondían a los intereses de las diferentes facciones de las clases dominantes. Ello implicó una suerte de relegamiento o exclusión de aquellas concepciones provenientes de las distintas líneas de la tradición marxista. En tal sentido, las categorías conceptuales y analítica desarrolladas por Antonio Gramsci y asumidas en distintos niveles y momentos históricos, por diversos intelectuales latinoamericanos, como es el caso de Paulo Freire, fue desplazada o simplemente negada como posibilidad explicativa e interpretativa.

Luego de la caída del Muro de Berlín en el año 1989, el capitalismo tanto en su expresión materialeconómica como en la dimensión ideológica configurada en los círculos académicos, cayó en una suerte de euforia triunfalista, llegando a declarar no sólo el fin de los "socialismos reales", sino también el "fin de la historia". En el ámbito de la reflexión y discusión académica, se vio limitada la posibilidad de instalar la discusión respecto del fenómeno de la hegemonía que se expresaba evidentemente en América latina, ya sea en lo que fueron las dictaduras militares o regímenes de facto en alianza con las diferentes facciones de la burguesía local que construyeron como bloque histórico dominante.

En los inicios de la década del noventa se produce un reencuentro con el pensamiento gramsciano, el cual por cierto ya se venía dando desde lo que fue el "seminario de Morelia", desarrollado en México en al año 1980. Esto constituye un esfuerzo intelectual de articulación de las construcciones teóricas gramscianas con la realidad de América Latina y sus posibilidades de generar una alternativa diferente a la hegemonía capitalista, de acuerdo al momento histórico y político que vivía el continente. La hegemonía material e intelectual se verá tensionada y cuestionada con la emergencia de los nuevos movimientos sociales y sus luchas reivindicativas, en tanto expresiones empíricas de las clases subalternas. El Ejército Zapatista de Liberación Nacional (EZLN) en México, el Movimiento de los Sin Tierra (MST) en Brasil, los piqueteros en Argentina, los movimientos indígenas en Bolivia y Ecuador, o la lucha reivindicativa del pueblo mapuche en el sur de Chile, interpela una revitalización y renovación de esta línea de teórica crítica. 


\section{Hegemonía, bloque histórico e intelectuales: De Gramsci a Freire}

Para comprender lo que Gramsci entiende por hegemonía, es necesario clarificar lo que es el bloque histórico. Esto no es del todo fácil, por el nivel de complejidad que implica traspasar los límites dogmáticos del marxismo-leninismo y del cientificismo economicista de corte más positivista. Por lo mismo es que Portelli plantea que no se puede concebir el bloque histórico simplemente "como una alianza entre clases sociales" (2003:10), por cuanto su nivel de complejidad y articulación no queda resuelto sólo en base a una alianza mecánica o instrumental entre las clases. En este proceso, confluyen expresiones materiales y subjetivas de los sectores, que logran constituirse como bloque dominante.

En el proceso de construcción del bloque histórico, se pueden distinguir tres momentos o escenarios distintos: el primero tiene que ver cómo se expresan las relaciones entre estructura y súper-estructura, sin que exista supremacía de una sobre la otra; el segundo momento se da cuando se logra la supremacía de la sociedad civil sobre la política y se construye un sistema hegemónico, bajo la dirección de una clase fundamental que confía su gestión a los intelectuales, que sería la consolidación del bloque histórico; el tercer momento se genera con el quiebre de la hegemonía de la clase dirigente, que conlleva a la construcción de un nuevo sistema hegemónico y se crea un nuevo bloque histórico.

La naturaleza de la hegemonía y por lo tanto cómo esta se expresa en el bloque histórico, tiene al menos dos aspectos claves a considerar: Primero que "la base de toda clase hegemónica es obra de una clase fundamental y esta clase es fundamental en todo periodo histórico considerado [y segundo] en la medida que el bloque histórico representa una situación histórica determinada, el análisis podrá referirse a una situación reducida o extensa" (Portelli 2003:81). De esta forma, el bloque histórico, entendido como una categoría implícita en el proceso de construcción de hegemonía, nos entrega elementos para el análisis y descripción de una determinada relación de poder y conflicto en una realidad histórico política concreta.

En el proceso de conformación del bloque histórico cobran relevancia los sentidos y significados que mueven la acción colectiva y, al respecto, Gramsci afirma que el proceso de formación de una determinada voluntad colectiva se orienta a un determinado fin político, lo cual "no se da por clasificaciones pedantes de principios y criterios de un método de acción, sino como cualidades, rasgos característicos, deberes necesidades, de una persona concreta (...) y da una forma más concreta a sus pasiones políticas" (2006:53). De ahí también sus críticas al positivismo economicismo marxista clásico o la teoría historiográfica, pero especialmente a la teoría y la práctica política. En tal sentido, la súper-estructura del bloque histórico se expresa como una totalidad compleja, constituida por la sociedad política que agrupa al aparato del Estado y por otro la sociedad civil (que no es homogénea), que representa la mayor parte de esta superestructura en su expresión material e intersubjetiva.

Portelli destaca que la sociedad civil expresa la concepción de mundo de las clases dirigentes y hegemónicas, pero sin embargo, es necesario clarificar que ello no se presenta de manera única e idéntica en el espacio y tiempo, sino que por el contrario presenta innumerables formas, que van desde el folklore, que sería la expresión más rústica de la ideología dominante, hasta la filosofía que sería el nivel más elevado del pensamiento ideológico del bloque histórico. El concepto de hegemonía contribuye, por lo 
tanto, a la comprensión de las relaciones de poder que se presentan en el orden económico, político, cultural e ideológico, en una determinada estructura social.

A juicio de Gramsci la hegemonía representa la supremacía lograda de la sociedad civil respecto de la sociedad política, en donde la primera corresponde a la mayor parte de la superestructura, conformada por las "llamadas organizaciones privadas, como la Iglesia, los sindicatos, las escuelas, etc." (Gramsci 2005:146). Vale clarificar que Gramsci se refiere a la sociedad política como el aparato del Estado, el que está conformado por los mecanismos coercitivos, como por ejemplo los Tribunales de Justicia, las cárceles, el ejército y la policía.

La sociedad civil logra el debilitamiento de la sociedad política y en consecuencia permite el "control ideológico sobre otros grupos (...) y por tanto de la coerción (...); la sociedad política se ve así reducida a un rol de apoyo y tiende incluso a integrarse parcialmente a la sociedad civil" (Portelli 2003:73). Dicho control, agrega Portelli, "se caracteriza fundamentalmente por la difusión de su concepción de mundo entre los grupos sociales -que deviene así 'sentido común'-y por la constitución de un bloque histórico al que corresponde la gestión de la sociedad civil" (2003:73). En este proceso los intelectuales juegan un rol importante, por cuanto están llamados a ser parte de la clase dirigente y a difundir su filosofía, constituyéndose por lo tanto en intelectuales orgánicos de las clases dirigentes. Asimismo, estos intelectuales orgánicos serían los encargados de ejercer las funciones conectivas, organizativas y de difusión ideológica, definidas desde en el interior del bloque histórico. En términos marxistas, estos intelectuales cumplirían una doble función: primero como cuadro político y, segundo, contribuyendo al proceso de formación de los nuevos cuadros.

\subsection{Praxis revolucionaria y praxis de las elites}

Como se planteaba más arriba, los intelectuales orgánicos serían los cuadros que contribuyen en la elaboración de las bases ideológicas, los propagandistas de la clase dirigente, una suerte de "empleados" del bloque dominante. Por lo tanto, se puede decir que la hegemonía se logra si tiene capacidad de formación de sus cuadros, de intelectuales elaboradores y difusores de la ideología de la clase que se ha constituido como fundamental. En Paulo Freire esto tiene una correspondencia epistemológica y política interesante, que se expresa en la construcción de un saber dialéctico entre la tensión que se materializa en la relación de las clases dominantes (opresores) y las clases subalternas o dominadas (oprimidos).

El paso decisivo de una conciencia dominante, de carácter transitiva ingenua, sólo se logra en la medida que se realice un trabajo educativo crítico. Aquí no solo juega un rol importante el intelectual, que llamaremos orgánico popular, sino que esto apunta a una transformación política y moral de la sociedad, sustentada en una relación dialógica y democrática. Por ello es que cuando las clases populares se redescubren como clase, también descubren las relaciones de dominación y opresión a las cuales han sido sometidas y en respuesta a esta conciencia crítica "las elites, asustadas, tienden a silenciar a las masas populares domesticándolos por la fuerza o con soluciones paternalistas" (Freire 2004:81), o por medios del aparato del Estado, con políticas sociales que se transformas en estrategias de contrainsurgencia social. 
Paulo Freire en Pedagogía de la Esperanza relata una experiencia vivida con un grupo de trabajadores campesinos, la cual nos permite poner en tensión una concepción y práctica del intelectual del tipo vanguardista, que se inclinaría más bien en una lectura marxista-leninista. Lo que relata Freire es lo que un trabajador campesino le interpela de la siguiente forma: "Necesitamos decirte, compañero, una cosa importante. Si viniste aquí pensando enseñarnos que somos explotados, no hace falta, porque nosotros lo sabemos muy bien. Ahora lo que nosotros queremos saber de ti es si tú vas a estar con nosotros, a la hora que caigan los palos" (Freire 2002:67).

Esta experiencia que relata Freire no sólo es un aprendizaje para él, sino que permite comprender la importancia que para este intelectual tienen los saberes populares y la relación entre el intelectual de la academia con el intelectual popular, que sin haber pasado por un proceso de aprendizaje formal, es poseedor de una sabiduría que le da su experiencia cotidiana. Ahí es donde se materializa esa dialéctica entre teoría y práctica, que Freire lo expresa en su concepto de praxis revolucionaria.

Para Gramsci la filosofía de las clases dominantes, y las instituciones que permiten la producción y reproducción, requieren de una respuesta contra-hegemónica desde las clases subalternas, para avanzar en la reforma moral que sustente la nueva hegemonía. Esto queda representado en diferentes pasajes de la extensa obra de Paulo Freire, relacionados con la necesidad de educar a las clases oprimidas para construir una nueva moral, basada en la libertad y el respeto, donde educadores y educandos construyen una relación dialéctica de aprendizaje mutuo, lo cual refleja la influencia del pensador italiano. Gramsci cuestiona la educación de carácter elitista y Freire por su parte, cuestiona lo que él denomina una educación bancaria, que constituye la expresión material y simbólica de las prácticas de dominación de las elites dominantes, "una práctica inmovilizadora y encubridora de verdades" (Freire 2002:95), que además desconoce a los hombres y mujeres como seres históricos y políticos.

Para Gramsci los intelectuales no sólo son aquellos grupos que representan la concepción elitista y clásica, sino que: "Por intelectuales hay que entender no [sólo] aquellas capas designadas comúnmente con esta denominación, sino en general toda la masa social que ejerce funciones organizativas en el sentido lato, tanto en el campo de la producción, como en el de la cultura, como en el campo administrativo-político" (1981:103).

A partir de esto es que resulta interesante la articulación de esta concepción con lo que Freire señala en torno la educación como ideología e instrumento de las clases dominantes para consolidarse como clase dirigente y hegemónica, que se expresa en la educación bancaria. Desde el bloque histórico se canaliza un tipo de educación diseñada por los intelectuales orgánicos, para el mantenimiento de las diferentes estructuras, formas de control, de dirección y dominación, y por cierto, una educación elitista que forma los futuros cuadros intelectuales de las clases dominantes. Como antítesis a esta educación bancaria, propone una educación liberadora, la cual en primera instancia genera las condiciones de ir cimentando una conciencia crítica, que "conduce a los oprimidos tarde o temprano, a luchar contra quien los minimizó" (Freire 2006:41). 
Para Gramsci la educación tiene gran importancia, por cuanto no sólo esta constituye un instrumento de reproducción de la ideología dominante y hegemónica, sino que desde la contra-hegemonía implica la posibilidad de educar a los sectores populares para la formación de sus cuadros de intelectuales, por lo tanto, el proceso de trabajo educativo-formativo contribuye a la elaboración de una conciencia crítica que "promueve y favorece sobre una determinada base histórica que contenga las premisas materiales para esta elaboración, [que] no puede limitarse a la simple enunciación teórica de principios 'claros' de método: esto sería pura acción iluminista" (Gramsci 1981:100).

La conexión entre el pensamiento de Gramsci y el desarrollo pedagógico-político de Freire lo podemos ejemplificar también en el contenido de una de las cartas enviadas por el italiano a su cuñada Tania el 22 de abril de 1929, donde le cuenta sobre un rosal que estaba cultivando en la cárcel y cómo estas rosas y sus hojas se estaban marchitando. En este diálogo epistolar, Gramsci pone en discusión el permanente conflicto que se presenta en el proceso educativo, en que por un lado se ubica un tipo de educación autoritaria, en que el educador asumiendo su autoridad deposita conocimientos en el educando sin reconocerle sus capacidades, sus historias de vida, sus propios saberes, y por otro lado, un tipo de educación democrática, participativa, dialéctica y crítica. En la carta mencionada, la analogía que hace Gramsci entre el jardinero y el educador refleja muy claramente ese dilema, en donde la ansiedad por pretender que la planta -que sería el estudiante- se desarrolle más rápidamente y de acuerdo a los intereses del profesor, puede significar anular completamente su identidad o simplemente domesticándola.

En esta línea Freire plantea que la educación es una práctica de dominación que está al servicio de las clases dominantes, por lo cual el desafío moral y político es transformar esa educación en una práctica para la liberación de todas las formas de opresión, lo cual coincide con lo que Gramsci desarrolla en los Cuadernos desde la Cárcel en torno a la educación y también el rol de los intelectuales.

Para Freire el conocimiento no es un mero producto, sino que es una construcción histórica, social y política. El conocimiento se manifiesta de manera dialéctica desafiando el objetivismo positivista y el subjetivismo idealista y más bien lo ubica en una dialéctica humanista. En Pedagogía del oprimido Freire no sólo cuestiona un tipo de educación que denomina "bancaria", de carecer autoritaria y al servicio de la clase dominante, sino que también cuestiona el subjetivismo y objetivismo. Al respecto dice: "Ni objetivismo, ni subjetivismo o psicologismo, sino subjetividad y objetividad en permanente dialéctica [y agrega] Confundir subjetividad con subjetivismo, con psicologismo, y negar la importancia que tiene en el proceso de transformación del mundo, de la historia, es caer en un simplismo ingenuo" (2002:49).

Otro pasaje que ilustra la mirada gramsciana sobre la educación queda reflejada en la carta que le envía desde la cárcel a su esposa Julia Schucht el 30 de diciembre de 1929, en que le manifiesta su preocupación por el desarrollo educativo de su hijo Delio, a esa fecha de 5 años de edad. En dicha carta Antonio Gramsci sitúa la educación no como una cuestión puramente mecánica, sino que advierte como "estos sistemas influyen en las masas populares como fuerza política externa" (2006:5), distinguiendo en el seno de la estructura ideológica aquellas organizaciones encargadas de la difusión de la ideología de la clase dominante que conforma el bloque histórico, como una "fracción cultural" en donde la Iglesia, la 
organización escolar y los organismos de prensa, son las instituciones más representativas de esa función productora y reproductora de la hegemonía.

Esto se puede ver reflejado en Freire en su concepto de educación bancaria, en la cual el proceso educativo se caracteriza por una relación autoritaria, dirigida desde las estructuras de poder, en que el educador cumpliría el rol del intelectual orgánico, que deposita "saberes" de acuerdo a los intereses de la clase dominante, aunque esto no siempre esté asumido conscientemente por el educador, siendo por tanto un oprimido no consciente.

Freire cuestiona este tipo de educación elitista y autoritaria, la cual a su juicio representa los intereses de las clases opresoras y no hace sino que reproducir las prácticas hegemónicas de ésta. Por ello es necesario transformar esta educación autoritaria, en una práctica educativa democrática, en la que coincide con Gramsci en que el educador primero debe ser educado o, en el lenguaje freiriano, el educador también debe ser liberado. La transformación del educador y el educando dan cuenta de la necesidad de la reforma moral e intelectual a la que hace referencia el intelectual italiano, que es lo que permitiría generar las condiciones para la transformación de la sociedad.

\subsection{La reforma moral de la sociedad: La educación como práctica de la libertad}

La relación entre educadores y educandos, tanto en Gramsci como en Freire, se expresan como una relación dialéctica y democrática, en donde el papel de los educadores representan el rol de "intelectuales orgánicos", que deberían estar al servicio de las clases oprimidas, por lo cual el proceso educativo estaría orientado a crear las condiciones para la transformación de la sociedad, que en definitiva significaría la construcción de una nueva hegemonía.

Para Gramsci, el marxismo como filosofía de la praxis, viene a superar las contradicciones y antagonismos del pensamiento filosófico y político de su tiempo: "El marxismo original era precisamente la superación de la más alta manifestación cultural de su tiempo, la filosofía clásica alemana (...) en el sentido de que la filosofía moderna no consigue elaborar un programa escolar según su visión del mundo y no consigue elaborar una cultura popular, sino que sigue siendo la cultura de una aristocracia intelectual" (1981 tomo II:135).

En la concepción de bloque histórico, Gramsci señala que las fuerzas materiales constituirían el contenido de éste y las ideologías su forma, por lo cual le asigna una destacada importancia a las creencias y conocimiento popular. Es esto agrega que "las fuerzas materiales no serían concebibles históricamente sin forma y las ideologías serían caprichos individuales sin las fuerzas materiales" (1981 tomo III: 160). Este planteamiento viene a reforzar su concepción de filosofía de la praxis contenida en el marxismo, lo cual se puede leer en Paulo Freire cuando este plantea que la teoría sería estéril sin la práctica y que la práctica sin una teoría que la respalde, sería ciega.

Podemos visualizar que la reflexión gramsciana en relación al pensamiento marxista ilumina el análisis que Freire desarrolla en su crítica a una educación elitista, que se expresa en la praxis de las elites (que denomina Freire), en donde las clases dominantes "prescriben y los dominados se guían por las 
prescripciones" (Freire 2006:163). De ahí que la praxis revolucionaria queda expresada en un tipo de educación emancipadora. La praxis revolucionaria se expresa en la reflexión y acción de los sujetos en el mundo para transformarlo. No hay praxis revolucionaria sin una educación liberadora, sin una educación que permita la superación de la contradicción opresor/oprimido. Una praxis revolucionaria se expresa en la comunión de los hombres y mujeres en la transformación cotidiana del mundo y de sus prácticas opresoras. Es la expresión material y subjetiva de la reforma moral de la sociedad.

Gramsci, al desarrollar su análisis respecto a la realidad de las universidades italianas, devela una relación de tipo vertical y autoritaria entre los profesores y estudiantes, a lo cual textualmente lo expresa de la siguiente forma: "en las universidades, el contacto entre maestros y estudiantes no está organizado. El profesor enseña desde la cátedra a la masa de su auditorio, expone su lección y se va (...) para la masa de los estudiantes los cursos no son más que una serie de conferencias, escuchadas con mayor o menor atención, todas ellas o sólo una parte (...) Cada maestro tiende a formar su 'escuela' tiene sus puntos de vista determinados [llamados 'teorías'] sobre determinadas partes de su ciencia que quisiera ver sostenidos por sus seguidores o discípulos" (1981:79).

Sin perjuicio de que Gramsci le asigna importancia a la relación más directa y permanente entre maestros y estudiantes, no hay que perder la perspectiva en cuanto a que la práctica vertical y autoritaria que devela el italiano, por un lado implica una práctica hegemónica de reproducción de la ideología y los intereses de las clases dominantes, y por otro lado, nos parece que ahí emergen elementos significativos para comprender lo que Freire denomina educación bancaria. Asimismo, a partir de tal distinción, también es posible poner en el análisis lo que vendría siendo una praxis de las elites y una praxis de las clases subalternas, es decir, en palabras de Freire, una praxis revolucionaria versus una praxis elitista.

Gramsci preocupado por el nivel de conciencia de las clases subalternas, señala que éstas aún "estando históricamente a la defensiva no pueden adquirir conciencia de sí más que mediante la negación, a través de la conciencia de personalidad y de los límites de clase del adversario" (1981:48). Esto Freire lo plantea en la relación oprimido/opresor, en donde refiere que en un cierto momento de esta relación de contradicción y dominación, el oprimido siente una admiración por el opresor, que se expresa en la siguiente referencia: "En cierto momento de la experiencia existencial de los oprimidos [hay] una atracción irresistible por el opresor. Por sus patrones de vida. Participar de estos patrones constituye una aspiración incontenible. En su enajenación quieren, a toda costa, parecerse al opresor, imitarlo, seguirlo (...) llegar a ser como el 'hombre ilustre' de la denominada 'clase superior'” (Freire 2006:65).

Como se puede apreciar, en los diversos planteamientos de Gramsci parece con recurrencia la importancia de las instituciones educativas, como una de las estructuras importantes para el bloque histórico y, por lo mismo, su análisis crítico a la educación de tipo elitista lo expresa de diferentes maneras, como por ejemplo lo que argumenta en el siguiente párrafo: "No basta la remisa de la 'difusión orgánica desde un centro homogéneo de un modo de pensar y de actual homogéneo' (...) La 'repetición' paciente y sistemática es el principio metódico fundamental. Pero la repetición no mecánica, material: la adaptación de cada principio a las distintas peculiaridades, el presentarlo y representarlo en todos sus aspectos positivos $y$ en sus negaciones tradicionales, organizando siempre cada aspecto parcial en la totalidad. 
Encontrar la identidad real bajo la aparente diferenciación y contradicción, he ahí la cualidad más esencial del crítico de las ideas o del historiador del desarrollo social" (1981:99).

Esa lectura gramsciana, en Pedagogía del oprimido de Paulo Freire aparece de muchas formas, lo cual lo sintetizamos en el siguiente párrafo: "La pedagogía del oprimido, aquella que debe ser elaborada con él y no para él, en tanto hombres y pueblos en la lucha permanente de recuperación de su humanidad. Pedagogía que haga de la opresión y sus causas el objeto de reflexión de los oprimidos, de lo que resultará el compromiso necesario para su lucha por la liberación, en la cual esta pedagogía se hará y rehará" (Freire 2006:42).

Pero las clases subalternas, que en palabras de Freire son los oprimidos, muchas veces acomodados o adaptados al sistema hegemónico, le temen a su propia libertad, por ello es que la liberación es un "parto doloroso". En Tal sentido dice Freire, "el hombre que nace de él, es un hombre nuevo, hombre que sólo es viable en y por la superación de la contradicción opresores/oprimidos, que, en última instancia es la liberación de todos" (2006:47). Lo planteado por Freire tiene mucho sentido con las reflexiones de Gramsci en los Cuadernos de la Cárcel, cuando señala que "las clases subalternas sufren la iniciativa de la clase dominante, incluso cuando se rebelan: están en estado de defensa alarmada. Por ello, cualquier brote de iniciativa autónoma es de inestable valor" (1981:27).

Este proceso de construcción de hegemonía, se da por medio de una reforma intelectual y moral que dé cuenta de una síntesis más elevada, de voluntad política colectiva de los sectores subalternos. Esta voluntad y acción colectiva debe fortalecerse en una "unidad ideológica que servirá como 'cemento' de esta nueva voluntad colectiva [que] fungirá como una religión popular" (Zermeño 1985:263), lo que implica además que la nueva situación histórica genera un cambio en la superestructura y sus representantes, en este caso los intelectuales, los cuales de acuerdo con Gramsci "deben ser concebidos también ellos como 'nuevos intelectuales', nacidos de la nueva situación, no como continuación de la intelectualidad precedente" (1986:302), que es lo que sustentará esa reforma moral, lo cual no debe ser una cuestión de carácter individual, sino que debe generarse como un proceso colectivo, una sociedad colectiva que se transforma. Por ello que la educación popular y emancipadora de Freire, contribuye en la praxis a esa reforma intelectual y moral, y por lo tanto, a la construcción de ese nuevo hombre y esa nueva mujer.

\section{Comentarios finales}

Para interpretar el actual escenario, estimamos necesario retomar la lectura gramsicana del pensamiento de Paulo Freire. En tal sentido, consideramos que la perspectiva humanista que se expresa en el marxismo gramsciano, es tomada por Freire para interpretar las formas de dominación que se expresaban en la realidad latinoamericana durante el siglo XX, cuestión que en lo substancial no ha variado hasta ahora. En tal sentido, Paulo Freire propone una pedagogía liberadora, la cual consiste en preparar o formar a las clases subalternas no para el trabajo, sino en un sentido profundamente humanista que conduzca a la transformación social. 
Lo interesante del actual escenario de conflictividad que están protagonizando las clases subalternas en gran parte de América Latina, pone en evidencia la fragilidad del neoliberalismo y su capacidad de mantener su hegemonía. El movimiento amplio social que denuncia la educación de mercado en Chile, que tuvo como protagonistas principales a los estudiantes movilizados durante el año 2011, ha constituido un verdadero paradigma, por cuanto no sólo viene a cuestionar una estructura fundamental para la producción y reproducción de la ideología dominante y asegurar la dirección y control del bloque histórico, sino que además, pone en evidencia la crisis de legitimidad de un modelo que parecía invulnerable.

Las movilizaciones de los estudiantes y de los diferentes actores de las clases subalternas, durante el año 2011, expresan una interesante articulación tanto discursiva como pragmática, de los postulados de Gramsci y Freire, referidos en términos muy generales a la construcción -aunque sea muy seminal- de proyectos contra-hegemónicos, teniendo como base del discurso político el cuestionamiento al modelo de educación de tipo bancario-mercantil. Por lo mismo, es que los estudiantes son categóricos al decir que el movimiento no es de carácter gremial, sino político, y su finalidad es la transformación de la sociedad neoliberal.

La educación constituye un campo de conflicto que resulta ser una trinchera importante para el bloque hegemónico, por cuanto tiene la importancia estratégica para el mantenimiento y la reproducción de la ideología que permita la dirección y control de aparato del Estado. Por lo tanto, socavar un espacio fundamental para las elites, implicaría una pérdida significativa de influencia, poder y control de la clase hegemónica y por cierto una ascendente politización activa de las clases subalternas, que permite avanzar en las transformaciones sustantivas del modelo de acumulación neoliberal.

\section{Bibliografía}

Freire, P. 2002. Pedagogía de la esperanza. Un reencuentro con la pedagogía del oprimido. Buenos Aires: Siglo XXI.

Freire, P. 2004. La educación como práctica de la libertad. Buenos Aires: Siglo XXI.

Freire, P. 2006. Pedagogía del oprimido. Buenos Aires: Siglo XXI.

Gramsci, A. 1981. Cuadernos de la cárcel. México: Ediciones Era.

Gramsci, A. 2005. Cartas desde la cárcel. Buenos Aires: Nueva Visión.

Gramsci, A. 2006. Política y sociedad. Santiago: Centro Gráfico Limitada.

Portelli, H. 2003. Gramsci y el bloque histórico. Buenos Aires: Siglo XXI.

Zermeño, S. 1985. Los referentes históricos y sociológicos de la hegemonía. En: J. Labastidas y M. del Campo (Comp.) Hegemonía y alternativas políticas en América Latina. México: Siglo XXI - UNAM, pp. 251278.

Recibido el 14 Mar 2014

Aceptado el $16 \mathrm{Jul} 2014$ 